\title{
Molecular characterization of human papillomavirus and mouse mammary tumor virus-like infections in prostate cancer tissue and relevance with tumor characteristics
}

\author{
BERJAS ABUMSIMIR ${ }^{1,2}$, MOHAMMED MRABTI ${ }^{3}$, ABDELILAH LARAQUI $^{3,4}$, AHMED AMEUR $^{3}$, \\ SAAD IBNSOUDA KORAISHI ${ }^{5}$, MOHAMMED MZIBRI ${ }^{6}$, MARYAME LAMSISI $^{2}$, YOUSSEF ENNAJI ${ }^{2}$, \\ IHSAN ALMAHASNEH $^{7}$ and MOULAY MUSTAPHA ENNAJI ${ }^{2}$
}

\begin{abstract}
${ }^{1}$ Pharmacological and Diagnostic Research Centre (PDRC), Department of Medical Laboratory Sciences, Faculty of Allied Medical Sciences, Al-Ahliyya Amman University (AAU), Amman 19328, Jordan; ${ }^{2}$ Team of Virology, Cancerology, and Medical Biotechnologies, Laboratory of Virology, Microbiology, Quality and Medical Biotechnologies/ETB, Faculty of Sciences and Techniques-Mohammedia, Hassan II University of Casablanca, Mohammedia 20650;

${ }^{3}$ Research and Biosafety Laboratory, Mohammed V Construction Teaching Hospital; ${ }^{4}$ Laboratory of Biology of Human Pathologies, Faculty of Sciences, and Genomic Center of Human Pathologies, Faculty of Medicine and Pharmacy, Bio-Path Laboratory, Faculty of Sciences, Agdal, Mohammed V University, Rabat 6203; ${ }^{5}$ Innovation Centre, LBM Laboratory, Faculty of Sciences and Techniques, Sidi Mohamed Ben Abdellah University-Fes, Fes 1796;

${ }^{6}$ Biology and Medical Research Unit, CNESTEN-Rabat, Rabat 1382, Morocco; ${ }^{7}$ Department of Biotechnology, Faculty of Science, University of Sharjah, Sharjah 27272, United Arab Emirates
\end{abstract}

Received November 10, 2021; Accepted January 11, 2022

DOI: $10.3892 / \mathrm{mco} .2022 .2530$

\begin{abstract}
The suspected roles of human Papillomavirus (HPV) and mouse mammary tumor virus (MMTV) infections in prostate tumor development were recently reported. To detect the frequency of HPV and MMTV-like infections and clinical correlates of tumor characteristics, DNA samples from 50 men treated at Teaching Hospital of Rabat City (Morocco) between June 2017 and February 2019, were genotyped and confirmed by Sanger sequencing. Eight infections of HPV18 and two infections of MMTV-like were detected, and $50 \%$ of patients were at a Gleason score of 6. A significant association between Gleason score and HPV or MMTV-like infection was noted $(\mathrm{P}=0.0008) ; 90 \%$ of patients with viral infections presented with T1 and T2 pathological stage tumors. Yet, no significant differences were found between infected and noninfected men regarding other pathological parameters including prostate-specific antigen (PSA), tumor histological stage, age at diagnosis
\end{abstract}

Correspondence to: Professor Moulay Mustapha Ennaji, Team of Virology, Cancerology, and Medical Biotechnologies, Laboratory of Virology, Microbiology, Quality and Medical Biotechnologies/ETB, Faculty of Sciences and Techniques-Mohammedia, Hassan II University of Casablanca, Quarter Yasmina, Mohammedia 20650, Morocco Email: m.ennaji@yahoo.fr

Key words: prostate cancer, mouse mammary tumor virus, human papillomavirus, prostate-specific antigen, gleason score, molecular evolution and radical prostatectomy treatment $(\mathrm{P}=0.2179,0.4702$, 0.8101 , and 0.9644 , respectively). The molecular evolution of HPV and MMTV in comparison with previously aligned sequences was discussed. Our findings provide a highlight on the correlations between the clinical-pathological parameters of prostate tumors and HPV and MMTV infections. Prospective studies with a wide sample size are needed for more statistical clarification of the association between viral infections with prostate tumor criteria.

\section{Introduction}

Prostate cancer is the second most frequently diagnosed malignancy (after lung cancer) in men worldwide, accounting for 1,276,106 new cases and causing 358,989 deaths $(3.8 \%$ of all deaths caused by cancer in men) in 2018 (1). Risk factors can increase the risk of prostate cancer among men which include age, obesity, smoking, and inheritance of risk alleles. Notably, prostate cancer incidence and mortality vary through different ethnic backgrounds. Among the many risk factors causing prostate cancer, several studies suggest that virus infections might be important risk factors (2). The role of human papillomavirus (HPV) in human tumors has been intensively studied for decades; the virus has been suggested to contribute seriously to the incidence of ovarian, uterine, and other female reproductive system tumors. HPV 16 and 18 contribute to malignant tumors especially cervical cancer, and these two types are considered high-risk for $70 \%$ of all cancers caused by HPV in general compared to other types of HPV, and these two types affect about $20 \%$ of the adult population in Western countries (3-5). 
Yet, there is some confusion regarding the presence of HPV infections in prostate cancer tissues and its role in the entire tumorigenesis process $(6,7)$, as research has confirmed the presence of HPV in both cancerous and healthy tissues. HPV infections have been frequently detected in prostate cancer tissues but the infection frequencies detected vary significantly. The most frequently detected high-risk HPVs in prostate tumors are HPV types 16 and 18 (8-10).

In addition, the retrovirus mouse mammary tumor virus (MMTV) has been suggested to induce or accelerate carcinogenesis of healthy breast tissues by proviral integration (11), but the implications of MMTV in various human tumors such as prostate cancer remain unclear.

The correlation between the presence of HPV 18 and MMTV infections in prostate cancer tissues and clinical tumor criteria has not been previously analyzed in Moroccan men. The present study aimed to detect viral infections of high risk HPV 18 and MMTV-like in prostate cancer tissues and to find correlations between these viral infections and tumor clinical criteria.

\section{Materials and methods}

Prostate tissue specimens. A total of 50 fresh prostate biopsies were obtained from 50 men who were evaluated at the Teaching Hospital of Rabat City (Morocco) between June 2017 and February 2019. Histological samples were obtained to confirm a diagnosis of the presence of prostate adenocarcinoma. Biopsies were obtained according to standard protocols by physicians directly. Along with the biopsies, every sample had the relevant attached clinical and pathological parameters including: age, date of diagnosis, date of biopsy, Gleason score, prostate-specific antigen (PSA) concentration of prostate tumors, and the vital status of the patients. The clinical characteristics of the prostate cancer patients are provided in Table I.

Required ethical approval was obtained from the Committee of Biomedical Research Ethics in Morocco (no. 3/2018/30 April/2018). All patients consented to participate in the study and their information was handled as anonymous according to the ethical standards.

DNA extraction and genotyping. DNA samples were obtained from prostate cancer tissues; $\leq 25 \mathrm{mg}$ of prostate tissue was placed into a sterile microcentrifuge tube, and DNA was extracted from the tissue samples using pure link Invitrogen Genomic DNA Mini Kit (Thermo Fisher Scientific, Inc.), according to the manufacturers' protocol. DNA extraction was performed at the place of biopsy collection (Research and Biosafety Laboratory, Mohammed V Construction Teaching Hospital, Morocco). Processing and genotyping took place at the Oncology and Virology Laboratory at the Faculty of Sciences and Techniques at Mohammedia, Morocco. DNA was quantified using the Nanodrop spectrophotometer (Thermo Fisher Scientific, Inc.). Samples with a DNA concentration of $20-50 \mathrm{ng} / \mu \mathrm{l}$ or above were selected to perform polymerase chain reaction (PCR). To evaluate the quality and integrity of the extracted DNA, a 268-bp fragment of the housekeeping $\beta$-globin gene was amplified using the GH20/PCO4 primer set as previously described (12). Oligonucleotides for $\beta$-globin amplification are provided in Table SI.
HPV detection (Fig. S1). The Specific HPV L1 gene was targeted by PCR using specific primers described elsewhere (13). The PCR reaction consisted of $25 \mu$ l total volume PCR reaction containing genomic DNA (8 ng), 2X Taq PCR Master Mix kit (Qiagen USA), $2 \mu \mathrm{mol}$ forward and reverse primers. PCR amplification was performed using a Perkin Elmer 2400 Thermal Cycler ${ }^{\circledR}$ (PerkinElmer, Inc.).

The amplification procedure for HPV-L1 gene amplification was as follows: initial denaturation at $94^{\circ} \mathrm{C}$ for $3 \mathrm{~min}$, followed by 35 cycles of denaturation at $94^{\circ} \mathrm{C}$ for $1 \mathrm{~min}$, annealing at $43^{\circ} \mathrm{C}$ for $1 \mathrm{~min}$, and extension at $72^{\circ} \mathrm{C}$ for $1 \mathrm{~min}$ and final extension at $72^{\circ} \mathrm{C}$ for $10 \mathrm{~min}$. HPV16 and 18 provided by the biology and medical research unit (CNESTEN) Rabat, Morocco were used as positive PCR control and Ultra-pure water as negative PCR control. Primers set data used in HPV-L1 gene amplification are provided in Table SII.

MMTV-like detection. The 356-bp env sequence of MMTV-like virus as described previously $(14,15)$ was targeted by PCR using specific primers: forward, GTAACACAGGCA GATGTAGG and reverse, GTATGAAGCAGGATGGGT AGA. The conditions for PCR were as follow: initial denaturation at $94^{\circ} \mathrm{C}$ for $3 \mathrm{~min}$, followed by 35 cycles of denaturation at $94^{\circ} \mathrm{C}$ for $1 \mathrm{~min}$, annealing at $54^{\circ} \mathrm{C}$ for $1 \mathrm{~min}$, and extension at $72^{\circ} \mathrm{C}$ for $1 \mathrm{~min}$ and a final extension at $72^{\circ} \mathrm{C}$ for $10 \mathrm{~min}$. Primer sequences and amplicon size expected of MMTV amplification are provided in Table SIII.

Sequence identification and molecular evolution analysis. PCR product sizes were confirmed by gel electrophoresis for $1.5 \mathrm{~h}$ at $70 \mathrm{~V}$ on $2 \%$ agarose. PCR products were purified using ExoSAP-IT $^{\mathrm{TM}}$ Express PCR Product Cleanup (Thermo Fisher Scientific, Inc.). Last purification was performed using BigDye XTerminator ${ }^{\circledR}$ Purification Kit (Thermo Fisher Scientific, Inc.). Bidirectional Sanger sequencing was performed using BigDye Terminator v1.1 Cycle Sequencing Kit (Thermo Fisher Scientific, Inc.).

Forward and reverse PCR primers used in PCR were used in Sanger sequencing performed by Genetic Analyzer 3130 (Applied Biosystems), All purification and sequencing were performed at the Innovation Centre Facility, Sidi Mohammed Bin Abdullah University of Fez (Fez, Morocco). Sequence identity recognition was performed by NCBI blast tools: https://blast.ncbi.nlm.nih.gov/moleblast/moleblast.cgi. In addition, the phylogeny analysis of the genotypes of the viruses was performed using MSA viewer built in NCBI-Blast tools, method: fast minimum evolution, max sequence differences $=0.75$.

Statistical analysis. We compared the frequency of HPV18 and MMTV-like infections among the subset of Moroccan men with tumor characteristic categories. Comparisons between infected and non-infected men against tumor characteristics of the prostate cancer (Gleason score, PSA concentrations, tumor stage, and age at diagnosis) were based on $2 \times 2$ or more Chi-squared analysis or Fisher's exact test to test for statistical significance. All statistical tests were two-sided, and all P-values of 0.05 or less were considered statistically significant. All analyses were conducted using the Minitab 17 (Coventry, UK). 
Table I. Clinical characteristics of the prostate cancer patients $(n=50)$.

\begin{tabular}{|c|c|}
\hline Characteristics & $\mathrm{n}(\%)$ \\
\hline \multicolumn{2}{|c|}{ Age at diagnosis/surgery (years) } \\
\hline$\leq 60$ & $7(14)$ \\
\hline$>60$ & $37(74)$ \\
\hline Unknown & $6(12)$ \\
\hline \multicolumn{2}{|c|}{ Preoperative PSA, ng/ml } \\
\hline$<2.5$ & $1(2)$ \\
\hline $2.5-10$ & $10(20)$ \\
\hline$\geq 10.0$ & $33(66)$ \\
\hline Unknown & $6(12)$ \\
\hline \multicolumn{2}{|c|}{ Pathological Gleason score } \\
\hline$<7$ & $11(22)$ \\
\hline $7(3+4)$ & $6(12)$ \\
\hline $7(4+3)$ & $8(16)$ \\
\hline$>7$ & $11(22)$ \\
\hline Unknown & $14(28)$ \\
\hline \multicolumn{2}{|c|}{ Pathological T-stage } \\
\hline pT1 & $14(28)$ \\
\hline $\mathrm{pT} 2 \mathrm{x}$ & $17(34)$ \\
\hline pT3x & $3(6)$ \\
\hline pT4 & $5(10)$ \\
\hline Unknown/pTx & $10(20)$ \\
\hline \multicolumn{2}{|c|}{ Radical prostatectomy } \\
\hline Yes & $16(32)$ \\
\hline No & $21(42)$ \\
\hline Unknown & $13(26)$ \\
\hline \multicolumn{2}{|c|}{ Alcohol consumption } \\
\hline Yes & $10(20)$ \\
\hline No & $32(64)$ \\
\hline Unknown & $8(16)$ \\
\hline \multicolumn{2}{|l|}{ Smoking } \\
\hline Yes & $18(36)$ \\
\hline No & $24(48)$ \\
\hline Unknown & $8(16)$ \\
\hline
\end{tabular}

PSA, prostate-specific antigen.

\section{Results}

Positive viral infections in prostate cancer tissues were determined (Fig. 1). Of the 50 patients diagnosed with prostate cancer, $8(16 \%)$ patients were confirmed to be infected by the high-risk human papillomavirus (HPV) 18 (Fig. 1B and C), and $2(4 \%)$ patients were infected by MMTV-like virus (Fig. 1D). No patient was infected with the two viruses at the same time.

As determined from Table II, the age of diagnosis varied among those infected by HPV 18 (58-75 years). The PSA concentrations also varied significantly $(6.56-26.16 \mathrm{ng} / \mathrm{ml})$. While the Gleason score for $50 \%$ of these patients was 6 ; the
Gleason parameter was unknown for 1 patient. Three patients were not analyzed for Gleason score. One patient was treated by radical prostatectomy, three patients were treated by hormone therapy, and 1 patient was treated by both. Regarding tumor stage at the time of biopsy, 4 men presented with stage 1 tumors, 3 presented with histological stage 3 tumors, and 1 patient had third stage tumor.

Those infected by the MMTV-like virus were aged 57 and 61 years. Both patients had low PSA concentrations (8.09 and $7.27 \mathrm{ng} / \mathrm{ml}$ ). One patient presented with a Gleason score of 6 and was treated by radical prostatectomy and presented with early stage 2 after histological evaluation of the tumor. The other patient was not analyzed for Gleason score and presented with tumor stage one at the time of biopsy, and was not treated at the place of therapy.

The clinical characteristics of the 10 men infected by HPV 18 or MMTV-like viruses are documented in Table II.

To explore the relevance between tumor parameters and infections by HPV 18 or MMTV-like virus, statistical significance tests were performed (Table III). Five patients infected by HPV 18 or MMTV-like had a Gleason score of 6. In contrast, 5 non-infected patients had the same Gleason score. There was a significant difference between Gleason score and infection by one of the two viruses analyzed $(\mathrm{P}=0.0008)$. Regarding PSA, 4 infected patients had a low PSA concentration less than $10 \mathrm{ng} / \mathrm{ml}$, and 4 had a moderate rate of PSA concentration and 2 patients presented with a high PSA concentration ( $>20 \mathrm{ng} / \mathrm{ml})$. In contrast, 7 prostate cancer patients among the 40 men not infected by any virus presented with a low PSA concentration, and 27 out of 50 had a PSA concentration more than $10 \mathrm{ng} / \mathrm{ml}$. No significant differences between viral infections and PSA concentration was noted $(\mathrm{P}=0.2179)$.

Nine out of 10 infected by viruses were at an early histological stage of the tumor (T1 or T2), at the same time 22 out of 40 of noninfected men treated for prostate cancer also presented with early tumor stage T1 or T2. No significant differences between viral infections and tumor stage were noted $(\mathrm{P}=0.4702)$. A total of $80 \%$ of the prostate cancer patients infected by viruses had an age range of more than 60 years. In addition, the majority of those not infected had the same range of age. No significant differences between viral infections and age at diagnosis/surgery was noted $(\mathrm{P}=0.8101)$. Three prostate cancer patients $(30 \%)$ infected by HPV 18 or MMTV-like viruses were subjected to radical prostatectomy while 13 non-infected patients $(33 \%$ of the study group) were subjected to radical prostatectomy. Eighteen patients were treated with hormone therapy or other types of medication. A phylogenetic pairwise tree for MMTV-like was constructed using the sequence data already registered in NCBI databases in comparisons with our study sequence (Fig. 2A and B).

The molecular evolution homology with other HPV 18 genotypes and MMTV-like is reported in Fig. 2A and B. Certain homologies of our sequence are demonstrated with genotypes found in the NCBI database. Our sequence meets the reference sequence at $4067-4078$ base pair (bp), the taxonomic classification of papillomaviruses in origin based on nucleotide similarity of the L1 gene. 
Table II. Clinical characteristics of the 10 men infected by HPV or MMTV viruses.

\begin{tabular}{lccccccc}
\hline ID & $\begin{array}{c}\text { HPV 18+ve } \\
\text { (Yes/No) }\end{array}$ & $\begin{array}{c}\text { MMTV+ve } \\
\text { (Yes/No) }\end{array}$ & $\begin{array}{c}\text { Age at } \\
\text { diagnosis (years) }\end{array}$ & PSA (ng/ml) & $\begin{array}{c}\text { Gleason } \\
\text { score }^{\mathrm{a}}\end{array}$ & $\begin{array}{c}\text { Treatment } \\
\text { Pathological } \\
\text { T-stage }\end{array}$ \\
\hline PR-04 & N & Y & 57 & 8.09 & 6 & RP & T2a \\
PR-01 & Y & N & 72 & 18.92 & 6 & RP+HT & T1c \\
PR-03 & Y & N & 67 & 24.25 & 0 & - & T3 \\
PR-08 & N & Y & 61 & 7.27 & 0 & - & T1c \\
PR-05 & Y & N & 67 & 17 & 6 & HT & T2b \\
PR-06 & Y & N & 67 & 11.8 & 6 & HT & T1c \\
PR-07 & Y & N & 75 & 9.99 & - & - & T2b \\
PR-18 & Y & N & 70 & 19.31 & 6 & HT & T1c \\
PR-10 & Y & N & 58 & 6.56 & 0 & HT & T2b \\
PR-13 & Y & N & 63 & 26.16 & - & RP & T1c \\
\hline
\end{tabular}

HPV, human papillomavirus; MMTV, mouse mammary tumor virus; PSA, prostate-specific antigen. Treatment: RP, radical prostatectomy; HT, hormone therapy. ${ }^{\text {aScore }}$ of 0 for Gleason score=not analyzed.
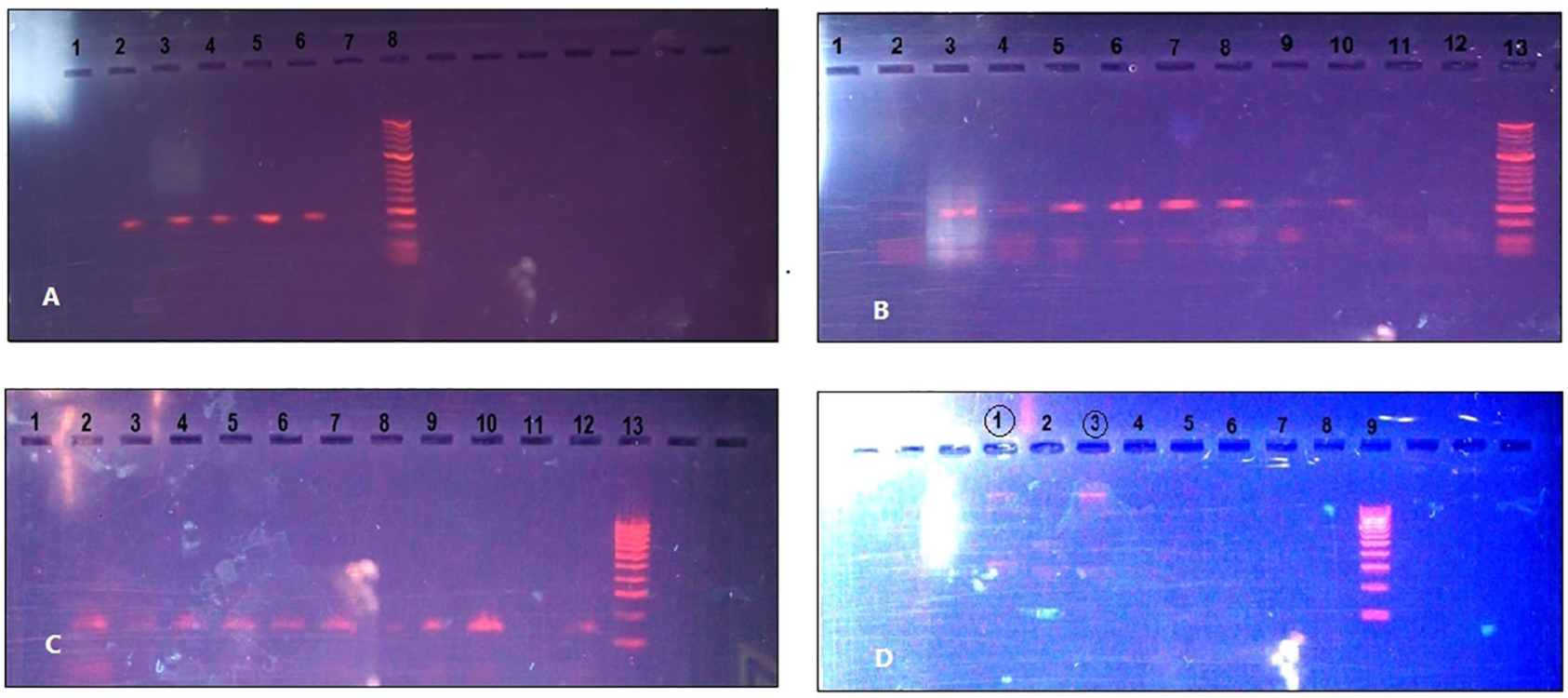

Figure 1. Positive viral infections in prostate cancer tissues. (A) 268 base pair (bp) $\beta$-globin fragments on gel (lanes 2-6, $\beta$-globin fragments; lane 7, negative control; lane 8, 50-bp DNA ladder). (B) HPV L1 450-bp fragment by MY09/MY11 primers on gel (lane 1, empty; lanes, 3, 4 and 10, positive samples; lanes 2, 9 and 11, negative samples; lane 12, negative control; lane 13, 50-bp DNA ladder). (C) HPV L1 142-bp fragment by GP5+/GP6+ primers on gel (Lane 1, negative control; lanes 2-10 and 12, HPV fragments; lane 13, 100-bp DNA ladder. (D) MMTV-like (MMTV1 and 2 primers) on gel (lanes 1 and 3, suspected positive samples; lanes 4-8, negative; lane 9, 100-bp DNA ladder). HPV, human papillomavirus; MMTV, mouse mammary tumor virus.

\section{Discussion}

Human papillomavirus (HPV) infections in healthy and cancerous prostate tissues have been previously reported, but vary in regards to infection frequencies among prostate cancer patients, with no absolute confirmation concerning a susceptibility role of HPV infections in prostate tumor development $(16,17)$. The present study findings concerning HPV 18, well-described as a high-risk genotype, reported $8 \mathrm{HPV} 18$ infections (out of the 50 prostate cancer patients) in the prostate cancer biopsies. Two mouse mammary tumor virus (MMTV) infections in the same subset of subjects were identified; MMTV infections in prostate cancer tissues have been rarely reported to date (18).
The association between tumor parameters and viral infections was also discussed, revealing a significant association between viral infections and Gleason score $(\mathrm{P}=0.0008)$. The majority of infected men (5 patients) had a Gleason score of 6 . From the pathological angle, scores of 6 or less describe cancer cells that look similar to normal cells and indicate that the cancer is likely to grow slowly. Furthermore, the tumor pathological stage for $90 \%$ of the infected patients was at stage one or two (T1 50\%, T2 40\%) which indicate that the prostate tumors were in the early stages of development. This indicates that viral infections were presented at an early stage as the tumors were being initiated. This led us to conclude that there is a possible 
Table III. Association between prostate tumor criteria and HPV 18, MMTV-like infected vs. non-infected patients.

\begin{tabular}{|c|c|c|c|}
\hline Tumor characteristics & Infected by HPV or MMTV-like $e^{\mathrm{a}}(\mathrm{n}=10)$ & Not infected $(n=40)$ & P-value ${ }^{b}$ \\
\hline Pathological Gleason score & & & 0.0008 \\
\hline$=6$ & 5 & 5 & \\
\hline$>6$ & 0 & 25 & \\
\hline Unknown & 5 & 10 & \\
\hline PSA & & & 0.2179 \\
\hline$<10$ & 4 & 7 & \\
\hline $10-20$ & 4 & 10 & \\
\hline$>20$ & 2 & 17 & \\
\hline Unknown & 0 & 6 & \\
\hline Pathological T stage & & & 0.4702 \\
\hline $\mathrm{T} 1$ & 5 & 9 & \\
\hline $\mathrm{T} 2$ & 4 & 13 & \\
\hline$>\mathrm{T} 3$ & 1 & 7 & \\
\hline Unknown & 0 & 11 & \\
\hline Age at diagnosis/surgery & & & 0.8101 \\
\hline$\leq 60$ years & 2 & 5 & \\
\hline$>60$ years & 8 & 28 & \\
\hline Unknown & 0 & 7 & \\
\hline Radical prostatectomy & & & 0.9644 \\
\hline Yes & 3 & 13 & \\
\hline No & 4 & 18 & \\
\hline Unkown & 3 & 9 & \\
\hline
\end{tabular}

${ }^{a}$ Based on infection of HPV or MMTV but not both. ${ }^{\text {b }}$ Chi-squared test or Fisher's exact test (excluding missing data). HPV, human papillomavirus; MMTV, mouse mammary tumor virus; PSA, prostate-specific antigen.

role of high-risk HPV genotypes or MMTV in the early development of prostate tumors. Yet, this result should be considered with restraint since other tumor criteria data especially the PSA concentration, tumor histological stage, age at diagnosis or radical prostatectomy treatment, were not significantly different between men infected by HPV 18 or MMTV-like vs. the non-infected men $(\mathrm{P}=0.2179,0.4702$, 0.8101 , and 0.9644 , respectively). In addition; we considered the tumor stage as a clinical parameter, while radical prostatectomy was considered as a pathological indicators; thus, the result of HPV and MMTV infections in those men treated with radical prostatectomy should be given special attention than viral infections in the clinical stages.

High homology of our sequence is demonstrated with genotypes previously described by Tirosh et al (18). The research mentioned has described the complete genome of HPV 18. Our sequence meets the reference sequence at 4067-4078 base pair (bp), the taxonomic classification of papillomaviruses in origin was based on nucleotide similarity of the L1 gene sequence. Analyzing the molecular evolution tree, the homology of MMTV-like sequence was concluded to be similar to this described by Tsiagbe et al (19), providing the complete coding region of the superantigen gene (SAG) in mouse models, meeting perfectly at 784-800 of the reference sequence.
The comparisons were inclusive to the targeted sequence superantigen gene (SAG). The homology of the superantigen was notable with MMTV 3' LTR-derived superantigen gene, and endogenous MMTV (RCS-MTV) superantigen gene from SJL/J mouse strain $(20,21)$, in addition to similarity with the sequence of the MMTV proviral DNA (from Mus musculus mammary gland) for gag-protease-pol polyprotein and env protein (19), and MMTV long terminal repeat region $(22,23)$. Concerning HPV sequences, the similar homology was with HPV isolated from humans in the USA (Fig. 2A and B) (24).

The origin of viral infections in the prostate has been a point of argument for years. Taken in mind that the associations between viral infections and prostate tumors has not been perfectly established yet, the circulation of such viruses between males and females should be considered, and further studies concerning the assumed circulation are important. The present study results revealed that HPV 18 or MMTV-like infections were found in the prostate gland early in tumorgenesis. Therefore, other studies with a wide sample size aimed at explaining the relationship between viral infections, on the one hand, and Gleason score and other tumor parameters, on the other hand, could be statistically meaningful to further confirm our conclusion. 


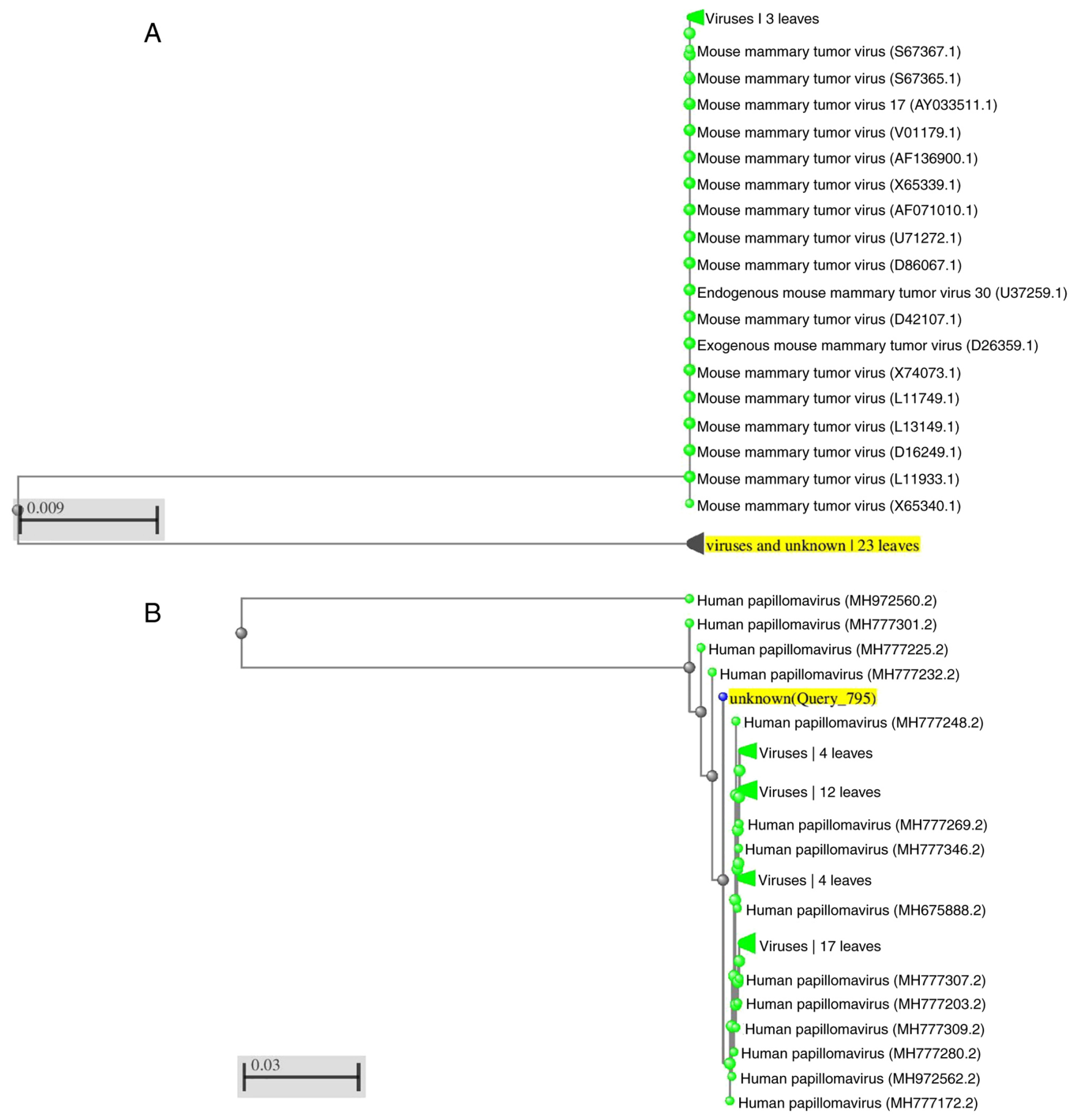

Figure 2. Distant tree pairwise alignment between HPV 18 (A) and MMTV-like (B) sequence results in this study and the database sequences already registered in NCBI GenBank. This analysis was performed using NCBI-Blast tools, method: fast minimum evolution, max sequence differences=0.75. The sequence results of this study are labeled in yellow color. HPV, human papillomavirus; MMTV, mouse mammary tumor virus.

\section{Acknowledgements}

The authors would like to thank the biopsy donors and their families, and many thanks to the members of the Virology, Oncology and Medical Biotechnology team at FSTM-Hassan II University of Casablanca, for all their efforts to support us during all work stages on this research.

\section{Funding}

No funding was received.

\section{Availability of data and materials}

The data generated in the present study may be requested from the corresponding author.

\section{Authors' contributions}

BA and MME conceived and designed the experiments. BA, $\mathrm{AL}, \mathrm{MMz}$ and MME optimized the experimental approach. BA, ML and YE performed the experiments. BA, ML, YE, IA and SIK analyzed all of the sequencing data and performed 
the statistical analyses. MMr, AL and AA managed the sample collection and processing the data and supervised the place in which all samples were stored. Proofreading and technical assistance were carried out by BA, IA, MME and wrote the manuscript. All authors read and approved the manuscript and confirm the accuracy of the data and agree to be accountable for all aspects of the research in ensuring that the accuracy or integrity of any part of the work are appropriately investigated and resolved.

\section{Ethics approval and consent to participate}

Required ethical approval was obtained from the Committee of Biomedical Research Ethics in Morocco (no. 3/2018/30 April/2018). All patients consented to participate in the study and their information was handled as anonymous according to the ethical standards.

\section{Patient consent for publication}

Not applicable.

\section{Competing interests}

The authors declare that they have no competing interests.

\section{References}

1. Ferlay J, Colombet M, Soerjomataram I, Mathers C, Parkin DM, Piñeros M, Znaor A and Bray F: Estimating the global cancer incidence and mortality in 2018: GLOBOCAN sources and methods. Int J Cancer 144: 1941-1953, 2019.

2. Blattner M, Lee DJ, O'Reilly C, Park K, MacDonald TY, Khani F, Turner KR, Chiu YL, Wild PJ, Dolgalev I, et al: SPOP mutations in prostate cancer across demographically diverse patient cohorts. Neoplasia 16: 14-20, 2014.

3. zur Hausen H: Human papillomaviruses and their possible role in squamous cell carcinomas. Curr Top Microbiol Immunol 78: $1-30,1977$

4. Faridi R, Zahra A, Khan K and Idrees M: Oncogenic potential of human papillomavirus (HPV) and its relation with cervical cancer. Virol J 8: 269, 2011.

5. Paavonen J, Naud P, Salmerón J, Wheeler CM, Chow SN, Apter D, Kitchener H, Castellsagué X, Teixeira JC, Skinner SR, et al Efficacy of human papillomavirus (HPV)-16/18 AS04-adjuvanted vaccine against cervical infection and precancer caused by oncogenic HPV types (PATRICIA): Final analysis of a double-blind, randomised study in young women. Lancet 374: 301-314, 2009.

6. McNicol PJ and Dodd JG: Detection of human papillomavirus DNA in prostate gland tissue by using the polymerase chain reaction amplification assay. J Clin Microbiol 28: 409-412, 1990.

7. Chen AC, Waterboer T, Keleher A, Morrison B, Jindal S, McMillan D, Nicol D, Gardiner RA, McMillan NA and Antonsson A: Human papillomavirus in benign prostatic hyperplasia and prostatic adenocarcinoma patients. Pathol Oncol Res 17: 613-617, 2011.

8. Yang L, Xie S, Feng X, Chen Y, Zheng T, Dai M, Zhou CK, Hu Z, Li N and Hang D: Worldwide prevalence of human papillomavirus and relative risk of prostate cancer: A meta-analysis. Sci Rep 5: 14667, 2015.
9. Ghasemian E, Monavari SH, Irajian GR, Jalali Nodoshan MR, Roudsari RV and Yahyapour Y: Evaluation of human papillomavirus infections in prostatic disease: A cross-sectional study in Iran. Asian Pac J Cancer Prev 14: 3305-3308, 2013.

10. Bae JM: Human papillomavirus 16 infection as a potential risk factor for prostate cancer: An adaptive meta-analysis. Epidemiol Health 37: e2015005, 2015.

11. Lawson JS and Glenn WK: Evidence for a causal role by mouse mammary tumour-like virus in human breast cancer. NPJ Breast Cancer 5: 40, 2019.

12. Resnick RM, Cornelissen MT, Wright DK, Eichinger GH, Fox HS, ter Schegget J and Manos MM: Detection and typing of human papillomavirus in archival cervical cancer specimens by DNA amplification with consensus primers. J Natl Cancer Inst 82: 1477-1484, 1990.

13. Lee SH, Vigliotti VS, Vigliotti JS and Pappu S: Validation of human papillomavirus genotyping by signature DNA sequence analysis. BMC Clin Pathol 9: 3, 2009.

14. Wang Y, Holland JF, Bleiweiss IJ, Melana S, Liu X, Pelisson I, Cantarella A, Stellrecht K, Mani S and Pogo BG: Detection of mammary tumor virus env gene-like sequences in human breast cancer. Cancer Res 55: 5173-5179, 1995.

15. Ford CE, Tran D, Deng Y, Ta VT, Rawlinson WD and Lawson JS: Mouse mammary tumor virus-like gene sequences in breast tumors of Australian and Vietnamese women. Clin Cancer Res 9: 1118-1120, 2003.

16. Medel-Flores O, Valenzuela-Rodríguez VA, Ocadiz-Delgado R, Castro-Muñoz LJ, Hernández-Leyva S, Lara-Hernández G, Silva-Escobedo JG, Vidal PG and Sánchez-Monroy V: Association between HPV infection and prostate cancer in a Mexican population. Genet Mol Biol 41: 781-789, 2018.

17. Dillner J, Knekt P, Boman J, Lehtinen M, Af Geijersstam V, Sapp M, Schiller J, Maatela J and Aromaa A: Sero-epidemiologal association between human-papillomavirus infection and risk of prostate cancer. Int J Cancer 75: 564-567, 1998

18. Tirosh O, Conlan S, Deming C, Lee-Lin SQ, Huang X; NISC Comparative Sequencing Program, Su HC, Freeman AF, Segre JA and Kong HH: Expanded skin virome in DOCK8-deficient patients. Nat Med 24: 1815-1821, 2018.

19. Tsiagbe VK, Yoshimoto T, Asakawa J, Cho SY, Meruelo D and Thorbecke GJ: Linkage of superantigen-like stimulation of syngeneic $\mathrm{T}$ cells in a mouse model of follicular center B cell lymphoma to transcription of endogenous mammary tumor virus. EMBO J 12: 2313-2320, 1993.

20. Sharma $P$ and Schreiber-Agus N: Mouse models of prostate cancer. Oncogene 18: 5349-5355, 1999.

21. Kang JJ, Schwegel T and Knepper JE: Sequence similarity between the long terminal repeat coding regions of mammary-tumorigenic BALB/cV and renal-tumorigenic $\mathrm{C} 3 \mathrm{H}-\mathrm{K}$ strains of mouse mammary tumor virus. Virology 196: 303-308, 1993.

22. Uz-Zaman T, Ignatowicz L and Sarkar NH: Mouse mammary tumor viruses expressed by RIII/Sa mice with a high incidence of mammary tumors interact with the Vbeta-2-and Vbeta-8-specific T cells during viral infection. Virology 314: 294-304, 2003.

23. Moore R, Dixon M, Smith R, Peters G and Dickson C: Complete nucleotide sequence of a milk-transmitted mouse mammary tumor virus: Two frameshift suppression events are required for translation of gag and pol. J Virol 61: 480-490, 1987.

24. Singh N, Josefsson A, Hussain S and Hugosson J: Human papillomavirus (HPV) infection as an emerging risk factor in prostate cancer. J Global Oncol 4 (Suppl 2) 2018. International (CC BY-NC-ND 4.0) License. 